\title{
Penyakit Fisik dan Lingkungan terhadap Insomnia bagi Lanjut Usia
}

\author{
Dudi Hartono $^{1}$, Sofia Februanti ${ }^{1}$, Ai Cahyati ${ }^{1}$ \\ ${ }^{1}$ Jurusan Keperawatan Poltekkes Kemenkes Tasikmalya \\ Email:duhar09@gmail.com
}

Submitted: 01-04-2019, Revised: 22-05-2019, Accepted: 12-06-2019

\begin{abstract}
Abstrak
Kebutuhan tidur merupakan kebutuhan dasar manusia termasuk lanjut usia (lansia). Namun banyak lansia yang mengalami kesulitan tidur (insomnia). Tujuan penelitian ini adalah untuk mengetahui hubungan penyakit fisik dan masalah lingkungan terhadap insomnia yang dialami lansia. Desain penelitian menggunakan cross sectional Pengambilan sampel dengan teknik purposive sampling, dengan jumlah 34 orang. Analisis data menggunakan univariat dan bivariat. Hasil penelitian menunjukkan bahwa terdapat hubungan antara penyakit fisik dan masalah lingkungan terhadap insomnia lansia.
\end{abstract}

Kata kunci: insomnia lansia, masalah lingkungan, penyakit fisik

\begin{abstract}
Sleep needs are basic human needs, including elderly. However, many elderly people have difficulty sleeping (insomnia). The purpose of this study was to determine the relationship of physical illness and environmental problems to insomnia experienced by the elderly. Research design using cross sectional Sampling with purposive sampling technique, with a total of 34 people. Data analysis using univariate and bivariate. The results showed that there was a relationship between physical illness and environmental problems with elderly insomnia.
\end{abstract}

Keywords: elderly insomnia, environmental problems, physical illness

\section{Pendahuluan}

Tidur merupakan salah satu aspek penting dalam kehidupan seseorang dan merupakan kebutuhan dasar yang dibutuhkan oleh semua orang. Insomnia dapat didefinisikan sebagai kesulitan untuk memulai atau mempertahankan tidur, ketidakmampuan atau ditandai kesulitan tidur di siang hari, lebih dari satu bulan. Insomnia dapat terjadi pada semua usia namun sering terjadi pada lansia (Bhasin, 2016). Insomnia merupakan salah satu masalah tidur yang paling sering terjadi pada orang dewasa tua (lansia).

Penelitian- penelitian menunjukkan bahwa masalah tidur pada lansia dapat timbul karena penuaan, selain itu dapat pula karena faktor psikologis dan biologis (El-Gilany, Saleh, El-Aziz, \& Elsayed, 2017). Insomnia dapat diklasifikasikan menjadi transient insomnia (terjadi dalam waktu lebih kurang seminggu karena perubahan lingkungan tidur, waktu tidur, depresi berat, atau stres); insomnia akut (karena penyakit fisik); dan insomnia kronik (karena penyakit psikologis seperti halusinasi) (Bhasin, 2016). Penyebab insomnia antara lain karena masalah lingkungan (ruangan terlalu penuh atau berisik, penggunaan alat elektronik seperti televisi atau ponsel), penggunaan obat- obatan (seperti alkohol, banyak mengkonsumsi kafein); penyakit fisik, kesehatan mental, dan sosial (seperti gangguan kecemasan, nyeri fisik atau ketidaknyaman, gangguan bipolar atau depresi) (Bhasin, 2016; Shrestha, Roka, Shrestha, \& Shakya, 2017).

Di dunia, angka prevalensi insomnia pada lansia diperkirakan sebesar 13-47\% dengan proporsi sekitar $50-70 \%$ terjadi pada usia diatas 65 tahun. Di Indonesia, angka prevalensi insomnia pada lansia sekitar $67 \%$ (Suastari, Tirtayasa, Aryana, \& Kusumawardhani, 2014). Tingginya angka insomnia pada lansia dapat menyebabkan berbagai dampak yang ditimbulkan.

Dampak tersebut antara lain merusak sistem kekebalan tubuh, jumlah sel darah putih, fungsi otak, dan variabilitas jantung. Selain itu, dampak insomnia juga dapat mempengaruhi suasana hati, kognitif, kelelahan, serta menunda pemulihan dan penyembuhan penyakit. Dampak- dampak yang ditimbulkan oleh insmonia dapat menurunkan kualitas hidup lansia (Valente, 2015; Suastari et al., 2014). Tujuan penelitian ini adalah untuk mengetahui karakteristik lansia, hubungan penyakit fisik dan masalah lingkungan terhadap insomnia yang dialami oleh lansia.

Metode

Desain penelitian yang digunakan adalah cross sectional. Penelitian dilakukan di Rumah Perlindungan Sosial Tresna Werda 
(RPSTW) Garut, selama bulan September sampai Oktober 2017. Pemilihan sampel menggunakan teknik purposive sampling dengan jumlah 34 orang lansia, dengan kriteria berusia minimal 60 tahun, dapat mendengar dan melihat, tidak mengalami demensia, dan tidak minum obat tidur selama seminggu terakhir, tidak mengalami gangguan jiwa. Teknik pengumpulan data dengan cara: calon responden yang sesuai kriteria dijelaskan informed consent. Setelah responden menandatangani informed consent, responden diberikan kuesioner untuk mengetahui adanya insomnia dan faktor yang berhubungan dengan insomnia lansia.

\section{Hasil}

Berdasarkan hasil penelitian yang telah dilakukan mengenai hubungan penyakit fisik dengan kejadian insomnia pada lansia di RPSTW Garut diperoleh sebagai berikut.

Tabel 1.

Karakteristik responden berdasarkan umur lansia di RPSTW Garut

\begin{tabular}{llll}
\hline Min & Max & Mean & Mean standar deviasi \\
\hline 60 & 87 & 70,75 & 7,638 \\
\hline
\end{tabular}

Usia terendah adalah 60 tahun, usia tertinggi 87 tahun, dengan rata- rata usia 70,75 tahun, dengan standar deviasi 7,638.

\section{Tabel 2.}

Karakteristik responden berdasarkan jenis kelamin, pendidikan, status marital, penyakit fisik,masalah lingkungan, masalah pikiran

\begin{tabular}{lll}
\hline Karakterisitik responden & f & \% \\
\hline Jenis kelamin: & & \\
Laki- laki & 15 & 44 \\
Perempuan & 19 & 56 \\
\hline Pendidikan: & & \\
Tidak tamat SD & 7 & 20 \\
SD & 19 & 56 \\
SMP & 3 & 9 \\
SMU & 4 & 12 \\
PT & 1 & 3 \\
\hline Status marital: & & \\
Menikah & 7 & 20,6 \\
Duda/ Janda & 27 & 79,4 \\
\hline Penyakit fisik: & & \\
Ya & 21 & 62 \\
Tidak & 13 & 38 \\
\hline Masalah lingkungan: & & \\
Ya & 7 & 20,6 \\
Tidak & 27 & 79,4 \\
\hline Masalah pikiran: & & \\
Ya & 9 & 16,1 \\
Tidak & 25 & 83,9 \\
\hline
\end{tabular}

Jenis kelamin lansia terbanyak adalah perempuan, pendidikan lansia terbanyak SD, status marital janda/ duda, memiliki penyakit fisik, tidak memiliki masalah lingkungan, tidak memiliki masalah pikiran.

\section{Diagram 1. Kejadian insomnia pada lansia di RPSTW Garut}

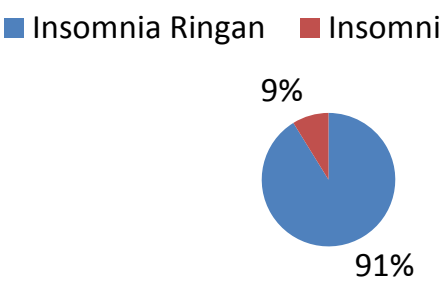

Berdasarkan diagram 1, diketahui bahwa persentase terbesar lansia di RPSTW Garut berdasarkan kejadian insomnia adalah memiliki kategori ringan yaitu sebanyak 31 orang $(91 \%)$.

Tabel 3. Distribusi frekuensi Penyakit Fisik dengan Kejadian Insomnia pada Lansia

\begin{tabular}{|c|c|c|c|c|c|c|c|c|}
\hline \multirow{3}{*}{$\begin{array}{c}\text { Penyakit } \\
\text { Fisik }\end{array}$} & \multicolumn{4}{|c|}{ Kejadian Insomnia } & \multirow{2}{*}{\multicolumn{2}{|c|}{ Jumlah }} & \multirow{3}{*}{$\chi^{2}$} & \multirow{3}{*}{$\rho_{\text {value }}$} \\
\hline & \multicolumn{2}{|c|}{ Ringan } & \multicolumn{2}{|c|}{ Berat } & & & & \\
\hline & $\mathrm{f}$ & $\%$ & $\mathrm{f}$ & $\%$ & $\mathrm{f}$ & $\%$ & & \\
\hline $\mathrm{Ya}$ & 18 & 64,3 & 3 & 10,7 & 28 & 100 & 6405 & 0,01 \\
\hline Tidak & 13 & 46,4 & 0 & 0,0 & 28 & 100 & 0,405 & 1 \\
\hline Jumlah & & 31 & 55,4 & 3 & 5,4 & 56 & 100 & \\
\hline
\end{tabular}

Berdasarkan tabel 3, diketahui bahwa pada lansia yang memiliki penyakit fisik persentase terbesar adalah memiliki kategori ringan dalam kejadian insomnia yaitu sebanyak 18 orang $(64,3 \%)$. Hasil uji statistik mengenai hubungan penyakit fisik dengan kejadian insomnia diperoleh nilai $\chi^{2}$ sebesar 6,405 dengan $\rho_{\text {value }}$ sebesar 0,011 . Hal ini menunjukkan bahwa nilai $\rho_{\text {value }}$ kurang dari $\alpha$ $(0,011<0,05)$, dengan demikian maka terdapat hubungan antara penyakit fisik dengan kejadian insomnia pada lansia di RPTSW Garut.

Tabel 4. Distribusi Frekuensi Masalah Lingkungan dengan Kejadian Insomnia pada Lansia di RPSTW Garut

\begin{tabular}{|c|c|c|c|c|c|c|c|c|}
\hline \multirow{3}{*}{$\begin{array}{c}\text { Masalah } \\
\text { Ling- } \\
\text { kungan }\end{array}$} & \multicolumn{4}{|c|}{ Kejadian Insomnia } & \multirow{2}{*}{\multicolumn{2}{|c|}{ Jumlah }} & \multirow{3}{*}{$\chi^{2}$} & \multirow{3}{*}{$\rho_{\text {value }}$} \\
\hline & \multicolumn{2}{|c|}{ Ringan } & \multicolumn{2}{|c|}{ Berat } & & & & \\
\hline & $\mathrm{f}$ & $\%$ & $\mathrm{f}$ & $\%$ & $\mathrm{f}$ & $\%$ & & \\
\hline $\mathrm{Ya}$ & 10 & 83,3 & 1 & 8,3 & 12 & 100 & & $0 \Omega-$ \\
\hline Tidak & 21 & 47,7 & 2 & 4,5 & 44 & 100 & 5,212 & 0,022 \\
\hline Jumlah & 31 & 55,4 & 3 & 5,4 & 56 & 100 & & \\
\hline
\end{tabular}

Berdasarkan tabel 4, diketahui bahwa pada lansia yang memiliki masalah lingkungan 
persentase terbesar adalah memiliki kategori ringan dalam kejadian insomnia yaitu sebanyak 10 orang $(83,3 \%)$. Hasil uji statistik mengenai hubungan masalah lingkungan dengan kejadian insomnia diperoleh nilai $\chi^{2}$ sebesar 5,212 dengan $\rho_{\text {value }}$ sebesar 0,022 . Hal ini menunjukkan bahwa nilai $\rho_{\text {value }}$ kurang dari $\alpha(0,022<0,05)$, dengan demikian maka terdapat hubungan antara masalah lingkungan dengan kejadian insomnia pada lansia di RPTSW Garut.

Tabel 5. Distribusi Frekuensi Masalah Pikiran dengan Kejadian Insomnia pada Lansia di RPSTW Garut

\begin{tabular}{|c|c|c|c|c|c|c|c|c|}
\hline \multirow{3}{*}{$\begin{array}{c}\text { Masalah } \\
\text { Pikiran }\end{array}$} & \multicolumn{4}{|c|}{$\begin{array}{l}\text { Kejadian } \\
\text { Insomnia }\end{array}$} & \multirow{2}{*}{\multicolumn{2}{|c|}{ Jumlah }} & \multirow{3}{*}{$\chi^{2}$} & \multirow{3}{*}{$\rho_{\text {value }}$} \\
\hline & \multicolumn{2}{|c|}{ Ringan } & \multicolumn{2}{|c|}{ Berat } & & & & \\
\hline & f & $\%$ & $\mathrm{f}$ & $\%$ & $\mathrm{f}$ & $\%$ & & \\
\hline $\mathrm{Ya}$ & 6 & 66,7 & 1 & 8,3 & 9 & 100 & & \\
\hline Tidak & 25 & 53,2 & 2 & 4,3 & 47 & 100 & 1,655 & 0,1 \\
\hline Jumlah & 31 & 55,4 & 3 & 5,4 & 56 & 100 & & \\
\hline
\end{tabular}

Berdasarkan tabel 5, diketahui bahwa pada lansia yang tidak memiliki masalah pikiran persentase terbesar adalah memiliki kategori ringan dalam kejadian insomnia yaitu sebanyak 25 orang $(53,2 \%)$. Hasil uji statistik mengenai hubungan masalah pikiran dengan kejadian insomnia diperoleh nilai $\chi^{2}$ sebesar 1,655 dengan $\rho_{\text {value }}$ sebesar 0,198 . Hal ini menunjukkan bahwa nilai $\rho_{\text {value }}$ lebih dari $\alpha$ $(0,198>0,05)$, dengan demikian maka tidak terdapat hubungan antara masalah pikiran dengan kejadian insomnia pada lansia di RPTSW Garut..

\section{Pembahasan}

Lansia mempunyai kecenderungan untuk mengalami insomnia. Lansia banyak mengalami perubahan salah satunya adalah perubahan neurologis. Akibat penurunan jumlah neuron fungsi neurotransmitter juga berkurang. Lansia sering mengeluh meliputi kesulitan untuk tidur, kesulitan untuk tetap terjaga, kesulitan untuk tidur kembali tidur setelah terbangun di malam hari, terjaga terlalu cepat, dan tidur siang yang berlebihan. Masalah ini diakibatkan oleh perubahan terkait usia dalam siklus tidur-terjaga. Perubahan yang sangat menonjol yaitu terjadi pengurangan pada gelombang lambat, terutama stadium 4, gelombang alfa menurun, dan meningkatnya frekuensi terbangun di malam hari atau meningkatnya fragmentasi tidur karena seringnya terbangun (Sumirta \& Laraswati, 2015).

Patofisiologi mengapa wanita lebih berisiko mengalami insomnia tidak diketahui dengan pasti, namun beberapa penelitian menduga kejadian insomnia pada wanita berhubungan dengan perubahan hormon, dimana penurunan kadar hormon estrogen dan progesterone diduga berhubungan dengan meningkatnya prevalensi insomnia (Susanti, 2015). Jenis kelamin wanita ditemukan lebih banyak mengalami insomnia pada penelitian ini.

Nyeri kronik atau penyakit fisik juga merupakan keluhan yang cukup sering ditemukan pada pasien insomnia dan berhubungan dengan kondisi yang tidak nyaman akibat nyeri. Pada sebuah penelitian, setelah dilakukan penilaian pada semua faktor, insomnia dan nyeri kronik dianggap memiliki hubungan timbal balik. Insomnia, nyeri kronis, dan depresi sering terjadi bersamaan dan merupakan kondisi yang saling berinteraksi. Namun, mekanisme yang mendasari gangguan komorbiditas ini belum dijelaskan. Beberapa penelitian menduga neurotransmitter serotonin dan norephinefrin memiliki peran besar memodulasi tidur, nyeri dan mood di sistem saraf pusat. Namun sebuah review terbaru menduga sistem Dopamine (DA) mesolimbik merupakan titik awal yang menarik dalam mengungkap hubungan antara insomnia, nyeri kronik dan depresi. Hal ini karena DA mesolimbik memiliki peran langsung dalam regulasi insomnia, nyeri kronik dan depresi (H.Finan \& T.Smith, 2013).

\section{Kesimpulan dan Saran}

Penelitian ini dapat disimpulkan bahwa responden dengan usia terendah adalah 60 tahun, usia tertinggi 87 tahun, dengan ratarata usia 70,75 tahun. Jenis kelamin lansia terbanyak adalah perempuan, pendidikan lansia terbanyak SD, status marital janda/ duda, memiliki penyakit fisik, tidak memiliki masalah lingkungan, tidak memiliki masalah pikiran. Persentase terbesar kejadian insomnia berada pada kategori ringan yaitu sebanyak 31 orang $(55,4 \%)$. Terdapat hubungan antara penyakit fisik dengan kejadian insomnia pada lansia dengan $\rho_{\text {value }}$ sebesar 0,011 . Terdapat hubungan antara masalah lingkungan dengan kejadian insomnia pada lansia dengan $\rho_{\text {value }}$ sebesar 0,022. Tidak terdapat hubungan antara masalah pikiran dengan kejadian insomnia pada lansia dengan $\rho_{\text {value }}$ sebesar 0,198 .

Sebaiknya Rumah Perlindungan Sosial Tresna Werda (RPSTW) Garut memiliki cara untuk mengatasi insomnia pada lansia terkait dengan penyakit fisik dan lingkungan.

\section{Daftar Pustaka}

Bhasin, H. (2016). Chronic insomnia \& its impact 
amongst adolescent. The International Journal of Indian Psychology, 3(4). Retrieved from

https://books.google.co.id/books?hl=id\&lr=\&id=J UojDQAAQBAJ\&oi=fnd $\&$ pg $=$ PA70\&dq=physica 1+disease,+environmental+causes+insomnia\&ots= WXstiRv_Zn\&sig=MV137Jq6sJQCbP-

41RRbBXVNULI\&redir_esc $=\mathrm{y} \# \mathrm{v}=$ onepage $\& \mathrm{q}=\mathrm{p}$ hysical disease $\% 2 \mathrm{C}$ environmental causes insomnia\& $\mathrm{f}=$ false

El-Gilany, A.-H., Saleh, N. M. H., El-Aziz, H. N. A., \& Elsayed, E. B. M. (2017). Prevalence of insomnia and its associated factors among rural elderly: a community based study. International Journal of Advanced Nursing Studies, 6(1), 56. https://doi.org/10.14419/ijans.v6i1.7415

H.Finan, P., \& T.Smith, M. (2013). The comorbidity of insomnia, chronic pain, and depression: Dopamine as a putative mechanism. Sleep Medicine Reviews, 17(3).

Shrestha, S., Roka, T., Shrestha, S., \& Shakya, S. (2017). Prevalence and Contributing Factors of Insomnia among Elderly of Pashupati Old Aged Home ( Briddhashram ). Mathews Journal of Psychiatry \& Mental Health, 2(2), 1-10.

Suastari, N. M. P., Tirtayasa, P. N. B., Aryana, I. G. P. S., \& Kusumawardhani, R. T. (2014). Hubungan antara sikap sleep gygiene dengan derajat insomnia pada lansia di poliklinik geriatri RSUP Sanglah, Denpasar. EJ Medika Udayana, 3(9).

Sumirta, I. N., \& Laraswati, A. I. (2015). Faktor Yang Menyebabkan Gangguan Tidur (Insomnia) Pada Lansia. Keperawatan Politeknik Kesehatan Denpasar, 20, 1-10.

Susanti, L. (2015). Faktor-Faktor Yang Mempengaruhi Kejadian Insomnia di Poliklinik Saraf RS DR . M . Djamil Padang. Jurnal Kesehatan Andalas, 4(3), 951-956.

Valente, S. (2015). Evaluating and Managing Insomnia : Non-pharmacological Treatments. Journal of Sleep Disorders \& Therapy, 4(2). https://doi.org/10.4172/2167-0277.1000189 